\title{
LEER EL FUTURO DEL LIBRO
}

\author{
Pablo Chiuminatto
}




\section{PABLO CHIUMINATTO}

Artista visual y académico. Doctor en Filosofía con mención en Estética y Teoría del Arte, y Magíster en Artes Visuales, Universidad de Chile. Actualmente es profesor de la Facultad de Letras de la Pontificia Universidad Católica de Chile, coordinador de proyectos digitales y miembro del Centro de Estudios en Literatura Chilena, CELICH. Desarrolla investigación formalizada en el campo de la historia de la cultura, hipermedios, iconología y estética. Miembro del Consejo del Observatorio del Libro y la Lectura. 


\section{LEER EL FUTURO DEL LIBRO}

En el diálogo Fedro, Sócrates aparece cuestionando una reciente invención: la escritura ${ }^{1}$. Se trata quizás de un vestigio privilegiado donde podemos identificar el miedo a los cambios asociados a la tecnología en la cultura occidental. La amenaza que representa este invento para Platón está asociado al cambio de las formas tradicionales de almacenaje, conservación y recuperación de los datos, es decir, la memoria. Su temor es que a partir de la escritura se producirá un enfoque en el soporte material de los datos, más que en la capacidad humana de remembranza, la articulación de los contenidos y las ideas en la forma tradicional del diálogo.

Volver sobre el testimonio de Platón nos sitúa ante una dinámica constante de la vida práctica. En palabras de George Simmel, "la tragedia de la cultura", definida sobre la disyuntiva resumida en la tensión entre la tradición y el cambio, lo antiguo y lo nuevo. En el caso de Platón, la escritura representa el fin de las formas arcaicas en las que se formó la escuela a la que pertenece. Dinámicas centradas en el diálogo, la memorización y la articulación oral del pensamiento. Ahora bien, paradójicamente el filósofo griego se encarga de dejar materializado los diálogos que eran el centro de la sabiduría de Sócrates y sus discípulos, por medio de esa escritura que rechazaba. Es decir, y no será el primero en la historia ciertamente, refuta esa nueva tecnología pero, al mismo tiempo, no duda en utilizarla. Su rechazo es más bien ideológico, su utilización también, aunque de un modo distinto.

Algo similar ocurrió durante el siglo XV, cuando con la invención de la imprenta como tecnología de reproducción de textos, los coleccionistas de manuscritos (códex) consideraron que la llegada los libros impresos representaba una amenaza para el conocimiento y las tradiciones asociadas a los volúmenes y libros producidos por los amanuenses. Por esta razón muchas de las nacientes casas editoriales mantuvieron prácticas que permitían al comprador personalizar el libro que adquirían: no tenían tapas ni cubiertas, por lo que había que empastarlos; ni traían las letras capitales, por lo que el comprador podía contratar un ilustrador para iluminar graciosamente el inicio de cada capítulo o párrafo; y mantenían una utilización exhaustiva de la página de acuerdo a la lógica de ahorro de los pellejos curtidos que eran más costosos y escasos que el papel con que en ese momento se hacían los libros.

La escritura y los procesos asociados a su circulación y divulgación han sufrido cambios constantes, algunos más importantes y radicales que otros, y siempre proporcionales con las formas de consumo o explotación para la obtención más eficiente del conocimiento. Unos, asociados a los soportes en que se escribe y lee, como piedra, cerámica,

1. Platón, Fedro, Madrid: Gredos, 1988, 368ss.

2. Simmel, G., "Sobre filosofía de la cultura: El concepto y la tragedia de la cultura", en Sobre la aventura. Barcelona: Península, 2002, 317-361. 
tablillas de cera, pergaminos, papel y, más recientemente, pantallas. Otros, relacionados con los materiales en que se representan los signos de lecto-escritura, como tallado, huella cuneiforme, tinta vegetal, mineral, óxido ferroso, tintas grasas, litográficas, offset y, últimamente, tinta digital. Los cambios están asociados al desarrollo de la tecnología que permite fijar los signos, pero, al mismo tiempo, a la materialidad de lo que acoge dicha información, el soporte.

Así, a grandes rasgos, somos testigos de un proceso de aproximadamente treinta y cinco mil años de tránsito entre tabletas de cerámica o cera, hasta la actual tableta digital y los teléfonos inteligentes que operan bajo un principio similar. En los tiempos de Platón, así como en el siglo XV cuando nace la imprenta (incunables, cuna de la imprenta), asistimos al enfrentamiento y tensión entre lo nuevo y lo antiguo, bajo una lógica de la tragedia de la cultura. Cada cambio repone nuevos desafíos y nuevos miedos. Ambos aspectos, lo nuevo y lo antiguo, poseen rasgos negativos y positivos, todo depende de la posición en la que se encuentra quien hace uso de los objetos resultantes, conocidos también como medios. Escritores, lectores, editores, librerías (tradicionales y digitales), libreros, bibliotecas (tradicionales y digitales), impresores, ilustradores, fabricantes de papel, vendedores de papel, críticos, coleccionistas, plataformas de contenido, entre otros. Un intrincado tejido social y cultural que en general no se piensa de forma integrada, sino binaria, como productores y usuarios, vendedores y compradores, objetos y disciplinas, grupos y culturas locales.

En el capítulo VI de la primera parte del Quijote de la Mancha, Miguel de Cervantes describe con agudeza el escrutinio que hacen de la biblioteca de Alonso Quijano el barbero y el cura. Los títulos dan cuenta de las fuentes bibliográficas en las que por años el anciano ha bebido con fruición los ingredientes de su delirio y explican el grado de erudición, a esa altura mal entendida, de la que nacen los desvaríos que fundamentan las aventuras del hidalgo. La escena es violenta, no solo desde el punto de vista de la sobrina y el ama de la casa, que piensan que eliminando la fuente de estos sueños se acabarán los desvaríos y alucinaciones del tío y patrón, asociados a la caballería. Como se mire, se trata de una feroz acción de censura, rematada con la quema de libros en el patio del solar. Sin embargo, hay algo particular en ese infortunio, en ningún momento, ni para el más culto ni el más ignorante de los personajes, se produce una identificación del mal que sufre Alonso Quijano con el libro como objeto. Para todos es claro que son los contenidos los que transportan al anciano hacia los delirantes confines de la Caballería Medieval, trescientos años después del contexto en el que dicha literatura trataba temas de tres siglos antes. El ejemplo nos permite volver sobre la dinámica trágica de lo nuevo y lo antiguo. Alonso Quijano es afectado por las alucinaciones caballerescas víctima de una transferencia de épocas. En muchos pasajes vemos que sus parientes, amigos, conocidos de aventuras y víctimas, intentan convencerlo que lo que está escrito en aquellos libros no es verdad. El Caballero de la Triste Figura es víctima del contenido de los libros, pero no padece un mal libresco. ¿Quién volvió loco al Quijote? ¿Los antiguos caballeros andantes, sus damas, los monstruos, o la página en la que estas creaturas fueron impresas y el dispositivo en que circula? 
A pesar del ejemplo cervantino hoy es posible identificar ciertos discursos acerca del futuro del libro y de la lectura con esta confusión entre el objeto y el contenido, los medios y la cultura, así como con el soporte que lo transfiere. Las quemas de libros no se decretan por ser libros, sino por lo que encierran. Son quemados por el potencial que representan para la estabilidad de ese lector transido por un universo convertido en realidad o en saber, ya sea como verdad o imaginación. La televisión en sí misma no es mala, son los contenidos los que determinan su contribución a la entretención o al aprendizaje, como núcleo cultural.

Cada soporte medial posee potenciales efectos positivos y negativos. La aparición de cada nuevo medio ha abierto un cúmulo de promesas para la formación de sus usuarios, consumidores, lectores, espectadores y audiencias. De ahí la propuesta bifronte de este ensayo. El desafío de una definición cultural basada en un principio de apertura al cambio, al mismo tiempo que con un fuerte sello de conservación que permita superar el binarismo de los pro y contra, relativizando además el carácter definitivo de los procesos. Una posibilidad quizás esté en asumir una perspectiva que abarque más que la discusión en particular del libro y la lectura, como es la cultura.

Zygmunt Bauman, siguiendo precisamente la propuesta de Simmel que mencionamos, hace un planteamiento claro en la introducción a la reciente reedición de su libro de mediados de los ochenta, La cultura como praxis, donde asume la disyuntiva a la que nos enfrenta la definición misma de cultura ${ }^{3}$. Primero, asociada a una variante activa del espíritu libre, sede de la creatividad, de la invención, de la autocrítica y de la autotrascendencia. Segundo, relacionada a un instrumento de continuidad al servicio del orden y la rutina, lo que llamamos, tradición. Es decir, la primera acepción, considera la cultura como poiesis, variación, la segunda como mimesis, repetición. Ambos polos independientemente emergen enfrentados por criterios de ruptura y conservación, lo que determina el concepto mismo de cultura como un orden que para su existencia requiere de un acuerdo, siempre transitorio. Principio que algunas voluntades sienten como un peso o lastre del que hay que deshacerse y otras como un acuerdo, marco necesario para la subsistencia. Bauman afirma la necesidad de teorizar acerca de esta "ambivalencia endémica del modo mismo de existencia de las culturas". Así lo arcaico y lo más nuevo se funden en una relación compleja en la que la dependencia marca el ritmo y el paso. Como bien explica Bauman, el epíteto de Simmel de "la tragedia de la cultura", se debe a que estos adversarios — conservación y novedad— "son parientes cercanos" 5 . De este modo, la tensión imaginada como una polaridad, como una bipolaridad, se necesita, tanto como se resiste. En cierto sentido bajo una dinámica de clan, antiguos y modernos, viejos y jóvenes, junto a lo funcional y lo obsoleto, no pueden compartir aparentemente el mismo espacio vital. Se repelen bajo la dinámica de una tribu donde quien pierde debe elegir entre el exilio o la muerte. Uno de los dos debe ceder, lo nuevo o lo tradicional debe desplazarse, o incluso replegarse completamente.

3. Bauman, Z., La cultura como praxis, Barcelona: Paidós, 2009, págs. 26-27.

4. Ídem 30.

5. Ídem 31. 
Sin embargo, sabemos que esto no se resuelve tampoco de un modo radical. Bauman siguiendo la metáfora clásica de Simmel, afirma, "lo fijo y atemporal [repetición] es la

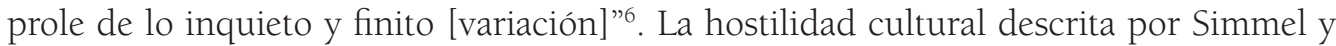
Bauman se adecua perfectamente al dilema actual del futuro del libro y la lectura. Donde sin duda, y la historia de la tecnología nos lo demuestra, lo más seguro es que ambos formatos sobrevivan hasta que un nuevo desplazamiento se haga cargo de poner el foco en una nueva zona en disputa.

Si seguimos con el ejemplo del Quijote, la novela de Cervantes no acaba con las novelas, ni con los libros, sino que viene a coronar un movimiento que ya había comenzado en el siglo XIV, con el surgimiento de otras corrientes de relatos centrados en temas profanos, amorosos, sociales, iniciados por G. Boccaccio y G. Chaucer. Asimismo con los soportes y dispositivos de lectura, la llegada del libro impreso no implicó la clausura inmediata de las formas tradicionales de transmisión del conocimiento. Habrá que esperar más de un siglo para que desaparezcan los oficios asociados a las formas clásicas manuscritas. De hecho, aún encontramos — aunque con dificultad- encuadernadores que desempeñan tareas diversas a la del restaurador. Sin duda se trata de un gran cambio, entre el anónimo y cubrir en piel y cartón los volúmenes para una biblioteca personal, hasta la guerra por la mirada del espectador de vitrinas, y los editores que buscan alcanzar la individualidad de las portadas. Sin duda este aspecto también lo cambiarán las librerías digitales que venden libros de papel, ya que su despliegue se alcanza en una miniatura de no más de algunos píxeles en la vitrina del navegador. El wishlist se vuelve una especie de limbo en el que descansa el deseo por las próximas lecturas. Del mismo modo como otros lectores hacen reservas y pedidos a su tradicional librero, otros reservan en las bibliotecas públicas o institucionales hasta que su temporal poseedor reintegre el libro. Las voces que se levantan escandalizadas por el deterioro de la cultura del libro y la lectura representan el porcentaje normal en que se divide esta bipolaridad cultural expresada en la fórmula de Simmel. La tragedia, su trama y alcance, está en lograr que la querella por la preeminencia entre los que están abiertos a los cambios asuman la transición y que los que los rechazan no desesperen mientras el nuevo escenario se vuelve un paradigma o incluso un lugar común. Sin embargo no deja de ser alarmante el discurso moralista de quienes critican esta ampliación de los medio digitales como el factor principal del deterioro cultural y educacional de las nuevas generaciones. Nunca antes en la historia del planeta más personas han sabido escribir y leer. Nunca antes tampoco más personas han leído y escrito. No obstante, en vez de enfocarnos en este nuevo escenario de las capacidades humanas, el centro de la discusión es el contenido de lo que leen, así como los dispositivos con que lo hacen. Sabemos que las próximas generaciones conocerán de la Internet principalmente a través de la telefonía inteligente, y que ya no será necesario que cada niño tenga un computador para poder acceder a una mejor formación ante los desafíos del siglo porvenir. Al respecto, hay una condición cognitiva que vale la pena considerar. En palabras de Martha Nussbaum: "Es probable que la tendencia a dividir al mundo entre lo conocido y lo desconocido resida en lo

6. Ibídem. Los paréntesis son nuestros. 
más profundo de nuestra herencia evolutiva"'. Bajo esta misma lógica, la querella por el futuro del libro y la lectura no escapa a dicha herencia.

La polaridad de la tradición y el cambio no es el único aspecto para la comprensión de las transformaciones que vive, y seguirá viviendo, el libro y la lectura. Nuevamente aquí es importante considerar otros hechos relacionados con un contexto más amplio, basta pensar en la penetración de las tecnologías de la información y comunicación (TICs) en la vida cotidiana. Los cambios son ingentes, constantes, las variables se suman día a día. Una de las características más relevantes con que se trata de describir la dinámica cultural de estas primeras décadas del siglo XXI ha sido la así llamada "Sociedad de la Información y el Conocimiento". A fines del siglo XX corrió mucha tinta para anunciarlo. Este encabezado se usaba en todo documento que estuviera abierto a la nueva perspectiva que implicaba la llegada del nuevo siglo de la mano de la Internet, y permeaba espacios académicos así como económicos. Hoy, que la primera década del siglo XXI ha pasado, cada día las tecnologías de la información y redes sociales tienen mayor presencia en los estudios relacionados con los cambios que implica su integración a nivel de producción, comunicación y conocimiento. Y, por cierto, su relevancia en los ámbitos de la economía y la sociología en cuanto ciencias culturales. Porque a diferencia de las formas de reflexión que se dieron acerca de la distribución de la información en los tiempos previos a la llegada de la Internet, hoy no tan solo debemos pensar en las formas de acceso al conocimiento y la cultura, centrada en los lugares y en los objetos, sino además en cómo se conserva ese conocimiento digital. Acceder a un libro ya sea por préstamo o compra, ir a una escuela o universidad, incluso poseer las habilidades para leer y escribir, registrar y transferir la información y el conocimiento siguen siendo las capacidades que permiten el acceso real, no solo de alcanzar sino de entender y ser autoconsciente de las formas y los saberes que constituyen la cultura a la que pertenecemos.

Hoy el desafío es más amplio, incluso más, el desafío se amplía en la medida que el acceso se hace más masivo y las plataformas digitales cubren áreas impensadas que permiten hasta cierto punto la liberación de los objetos que mediaban originalmente dicha experiencia y las instituciones que los administraban como contenidos físicos. Las voces que se levantan escandalizadas por un fenómeno de analfabetismo funcional derivado del acceso oral y audiovisual a la información es la nueva culpa que se le asigna a estos tiempos digitales. Se habla de la "Sociedad de la Imagen", como si se tratara de una fase decadente de la sociedad humana. Los lamentos que afirman que antes no era así, que los jóvenes de hoy leen cada vez menos, que escriben cada vez peor, que los contenidos son cada vez más pobres. Afirmaciones que vuelven sobre el mismo modelo de desprecio entre lo nuevo y lo antiguo que planteamos al inicio de este ensayo. No se trata que la información que arrojan las estadísticas sea falsa, el problema es el foco de

7. Nussbaum, M., Sin fines de lucro: por qué la democracia necesita de las humanidades, Buenos Aires: Katz, 2010, pág. 65.

8. Mansell, R., Wehn, U., Knowledge Societies: Information Technology for Sustainable Developmen, Oxford: Oxford University Press, 1998. Véase también: UNESCO, "Hacia las Sociedades del Conocimiento", coord. Günther Cyranek, 2005, véase online en http://unesdoc.unesco.org/images/0014/001419/141908s.pdf 
la consulta. ¿Qué entendemos por comprensión lectora: la repetición exacta de la información? Por qué no aceptar que existen grados de apropiación, que pueden ir desde la convergencia hasta la divergencia, pasando por áreas asociativas relacionadas con el conocimiento previo del lector. Pero la pregunta que habría que hacerse no se deriva de cómo volvemos a los antiguos tiempos en que la gente sabía leer y escribir bien; ya que es evidente que en esos tiempos dorados la cantidad de personas que tenían acceso a una alfabetización efectiva era proporcionalmente inferior. Por lo que, a pesar del debilitamiento de las capacidades actuales, dichos estratos sociales o grupos humanos simplemente no podrían haber suscrito siquiera a un alfabetismo funcional, eran simplemente analfabetos. Nuevamente, en este aspecto, lo que debiera equilibrarse no solo tiene que ver con una nostalgia respecto del ideal en que se formaron la clase media y alta durante el siglo XX. La verdadera pregunta radica en cómo es posible mantener los estándares idealizados por la crítica actual respecto de aquellos contextos. Hoy se escribe y lee mucho más que antes. Nunca antes se habían publicado tantos textos y exigido a las personas vincularse con interfaces de diálogo escrito como hoy. A pesar de eso, se resalta la información negativa, aquella que dice que estamos en un franco declive del potencial cognitivo y cultural. Sin duda, como señala Martha Nussbaum, el problema no está en que las personas hayan dejado de leer, sino en los objetivos que están detrás de las últimas reformas educacionales a nivel global centradas en la formación de capital humano enfocado únicamente en el reemplazo de áreas productivas, vinculadas a las ciencia y la tecnología, en desmedro de áreas que antes cubrían aparentemente zonas blandas de los currículos educacionales, como las artes y las humanidades. El proceso está en plena instalación. Los bajos índices en las evaluaciones que miden la capacidad de lectura y escritura en países pertenecientes a la OCDE, ni siquiera pensando más allá de esta pseudo-cúpula del desarrollo, están bajo el mismo prisma. Sin embargo, el foco se pone en la tecnología misma como la culpable de este deterioro. Nuevamente se confunde el objeto con el contenido, el medio con lo mediado.

La tendencia hacia la de incorporación de tecnologías de la información y conocimiento (TICs) y la interacción remota a través de las redes sociales no tiene vuelta atrás. Podrá cambiar el nombre, las fusiones de marcas y plataformas estarán en poder de una u otra gran compañía, pero no es posible proyectar su desaparición solo porque a algunos les parezca reprochable su uso. La penetración de las TICs en la cotidianeidad es ya una constante: telefonía celular, audio (mp4 o ipod), tablets, e-readers, notebooks, y televisión inteligente. Los jóvenes nacidos en los últimas dos décadas y que han crecido como "nativos digitales" viven de manera compleja la transformación de las capacidades de concentración y atención, lectura y escritura, tradicionalmente usadas en el contexto educativo y de ocio\%. A esta situación de las TICs, se suma el incremento exponencial de información disponible en la web, y la consiguiente dificultad para abordar, en términos metodológicos, estos verdaderos cardúmenes de información. La frase de Sócrates, "solo

9. Véase: Prensky, M., "Digital Natives, Digital Immigrants", On the Horizon 9 (5), 1-6, 2001. Bennett, S., Maton, K. y Kervin, L., "The 'digital natives' debate: A critical review of the evidence", en British Journal of Educational Technology, 39 (5), 2008, 775-786. 
sé que nada sé", hoy tiene una variante cuantitativa: solo sé que a pesar de un mejoramiento de la tecnología de la información no alcanzaré a saber lo que se sabe. Por esta razón, es urgente lograr reducir la hostilidad hacia las nuevas formas de acceso a la información y lograr apoyar el duro proceso que viven ambas falanges del problema, la tradición y la innovación. Tal como para Sócrates, la actualización tecnológica de la sentencia conlleva una ansiedad esencial. En ningún caso esto tiene relación con la edad cronológica de los usuarios, hay viejos tecno y jóvenes análogos. Una cosa no quita la otra, eso ha sido siempre así, desde los tiempos de Sócrates. La consideración además debe incluir la angustia que vive cada uno de los segmentos protagonistas de la transformación tecnológica del libro y la lectura. Por una parte, los antiguos ven su mundo análogo e impreso sucumbir al universo líquido de la tinta digital y las pantallas electrónicas. Por otra, los jóvenes que crecen en la constante de la obsolescencia no solo de los contenidos, sino además de los dispositivos, no alcanzan a ver consolidado su mundo cuando ya se hace anacrónico. Ambos principios de comportamiento cultural pueden definirse como angustiantes para quienes los experimentan. Todos pierden algo, por eso es necesario apoyar una reflexión crítica que supere la disputa de antiguos y modernos, análogos y digitales, manuales y tecnos, para alcanzar una solidaridad cultural mutua que ayude a vivir mejor un proceso inevitable de aceleración.

El crecimiento constante de información disponible online, junto a una creciente especialización de las disciplinas, expande la brecha que separa las capacidades de las nuevas generaciones. De este modo surge la necesidad de establecer sistemas que permitan vincular las nuevas potencialidades de estos nativos digitales con las habilidades propias exigidas por el perfil de conocimiento tradicional, generando una relación sinérgica entre las nuevas tecnologías y la tradición cultural. El incremento exponencial de información disponible en la web, y la consiguiente dificultad para los usuarios, comprende no solo un desafío para la inclusión de TICs en las dinámicas para la formación, sino también un problema de gestión de contenidos. No solo aquellos que son ofrecidos por las distintas plataformas con que entramos en contacto para conseguir información general, como los buscadores o administradores de contenidos (Google, Yahoo, entre otros), sino también de la gestión de la información que vamos almacenando y que ya trasciende los computadores personales. Por esta razón, es urgente generar métodos para asegurar las vías de acceso al conocimiento, estableciendo niveles segmentados que apoyen de forma pertinente las necesidades de la población a través de un pertinente filtraje y la validación de la información. Además de una comprensión de los procesos y criterios de almacenaje, propiedad y privacidad. Ya no tan solo buscamos asegurar el acceso a la información sino cómo capacitar para una autoconciencia del usuario respecto de los procesos de la información. Del mismo modo como Sócrates buscaba promover un pensamiento que comprendiese el proceso mismo de pensar.

Ahora bien, la información, en un mundo interconectado, como todo flujo, requiere de una organización. Y tal como ocurrió con el conocimiento y la administración de su circulación en todos los formatos previos a lo digital distintos grupos buscan su control. Desde hace algunos años ya que se escuchan voces sobre la necesidad de legislar para impedir el monopolio digital. Robert Darnton en su libro del año 2009, The Case for 
Books, analiza no solo el futuro de las bibliotecas sino también la necesidad de pensar el futuro digital en términos legales ${ }^{10}$. Esto, ante el hecho que se necesita apoyar el derecho a la información y las vías ante un acervo que supera lo que busca el usuario. Siempre encuentro más de lo que busco. Esto se hace evidente en la crisis de las categorías mismas que experimentan las bibliotecas hoy en día, donde los parámetros más recientes de lo así llamado interdisciplinario, multidisciplinario o innovación, entre otras, quiebran necesariamente las propuestas de J. Dewey o S. R. Ranganathan que iluminaron el ordenamiento de los contenidos bibliográficos de Oriente y Occidente por más de un siglo.

La urgencia por encontrar un eje de solidaridad que guíe el proceso de adopción tecnológica implica además considerar criterios cognitivos así como emocionales vinculados a la experiencia de temor que describimos desde el inicio de este ensayo. Quien lee ya no solo busca libros, compra libros, sino que administra contenidos de modo ampliado o, más bien, segmentados según los dispositivos que utiliza. Quien siente que su mundo está migrando hacia estas nuevas situaciones culturales sospecha que no encontrará el libro en su formato acostumbrado, o que no encontrará la librería, la biblioteca, el librero o el bibliotecario con el que acostumbraba discutir sus dudas, intereses y fobias. Pero eso que parece siempre nuevo tiene un antecedente. Los cuentos en sus versiones electrónicas son vendidos por entregas individuales en plataformas como Amazon, Oyster, Nook, entre otras, las que ofrecen día a día más facilidades de acceso a la compra de libros digitales. Ya no tan solo no es necesario esperar al día siguiente para ir a la librería y ver si está el libro que buscas, lo puedes comprar a cualquier hora, desde cualquier lugar, sin necesidad de esperar que lo encarguen, que llegue, y que el correo lo traiga a casa o a la librería más cercana. Para algunos lectores esto es la descripción de un hecho asociado a la transformación voraz del mercado internacional y el comercio online. Para otros es la descripción de una distopía feroz que solo puede terminar con el fin de la cultura e incluso del mundo como hábitat. Por una parte, todo parece hacerse más cercano, por otra, vemos eliminada la mediación humana en los procesos de búsqueda e intercambio. Sin embargo, si hacemos un poco de historia esto no es tan distinto de la literatura de cordel del siglo XVII, que se vendía, tal como su nombre lo dice, en las ferias y mercados locales; o de las novelas por entrega del siglo XIX que aparecían cada semana o mensualmente en los kioscos y librerías. Las voces que se alzan para anunciar el fin de la cultura siempre son más sonoras que aquellas que se permiten navegar por las complejas corrientes de la dependencia tecnológica aún no consolidada ni estable.

El libro obviamente es un objeto consolidado, un dispositivo con más de setecientos años de desarrollo. Los libros digitales no poseen la misma perfección y se debe a la falta de tiempo, estamos antes sus primeras conformaciones como objeto y medio. De hecho, lo más seguro es que los libros efectivamente "del futuro" se alejen o, al menos, se particularicen respecto de su antecesor impreso. ¿Tal vez no? De alguna manera tampoco es posible que la transición eterna de ambos objetos necesariamente elimine por completo su predecesor. Finalmente, entre una tableta de cera y un Kindle hay más similitudes que diferencias. Entre los volúmenes (libros en rollo) y el scroll de las pantallas de compu-

10. Darton, R., The Case of Books: Past, Present, Future, New York: Public Affairs, 2009. 
tadoras, hay mucho en común ${ }^{11}$. Entre la Enciclopedia Británica y Wikipedia, también. La pregunta radica en por qué se polariza la recepción de estos cambios. La hostilidad contra los avances tecnológicos asociados a dichas transformaciones o a la idea de que el libro electrónico resulta un perfeccionamiento técnico lógico obvio luego de siglos de otros tipos de cambio, no tiene matices. Entre una imprenta de tipos móviles y una máquina offset de alta velocidad hay un cambio visible en la calidad del libro resultante y todos fuimos felices mientras la calidad visual del texto mejoraba. Tal vez la distancia no es la misma que respecto a la interfaz del Kindle, pero el principio de visualización es cercano. La sospecha radica en por qué surge un fantasma tan potente populariza la creencia en una voluntad, una entelequia apocalíptica que estaría detrás de estas formas de desarrollo tecnológico. Como si en algún lugar del planeta se planeara el fin del libro impreso y las formas tradicionales de conocimiento asociado a la lectura, incluso a lo manuscrito. Una especie de Grinch, el personaje creado por Dr. Seuss en 1957, y que fue plasmado en el libro infantil titulado Cómo el Grinch robó la Navidad, concebido como una parodia de lo que el comercialismo de la Navidad produce. Con la precisión que el Grinch actúa bajo la economía del trauma y aquellos que se oponen a la tecnología asociada al desarrollo del libro digital y la lectura en soportes electrónicos opera ante el miedo a lo desconocido. El personaje hace referencia al consumismo y a la preocupación solo por lo material que socava el sentido de la fiesta en sí. De alguna manera, la reacción a priori que se manifiesta en el rechazo a los cambios que vive el libro y las formas de acceso a la lectura reviven este horror. Como si el sentido del libro y la lectura estuviera en el objeto libro, tal como lo concibieron las últimas cuarenta generaciones y no el formato en el que las nuevas lo reciben. Lo mismo debiera darse para el fin de las cartas, tarjetas postales y esquelas, ante una corriente de virtualización de las comunicaciones. Sin duda, muchos se opusieron al telégrafo, que en paz descansa. Otros al teléfono y su capacidad de acabar con las cartas y tarjetas de agradecimientos. Pero la distorsión es generalizada. El foco de la discusión no se centra en cómo lograr instancias de solidaridad que medien la experiencia angustiante que describimos, propia de la obsolescencia generalizada de contenidos como de dispositivos tecnológicos asociados al conocimiento.

Ambas riveras están necesitadas de la promoción de instancias para remediar la sensación de pérdida y futilidad. Los jóvenes que viven el vértigo de un panorama siempre cambiante, en ciclos cada vez más breves. Los adultos, aquejados por el naufragio de lo conocido. No se trata de alcanzar un consenso, una negociación, porque es inútil tratar de acercar el vértigo de lo desconocido a la experiencia que es su opuesto. Unos porque no lo han vivido, los otros porque no quieren perder lo que ha costado tanto. Ahora bien, ¿quiénes son los indefensos? Quizás ambos, cada uno afectado por cierto mal, uno congénito, el otro degenerativo. La pregunta está en si lo que se está poniendo en crisis no es el modelo general de la cultura y que el temor no es más que un síntoma de dicho proceso. En ese sentido, la ampliación de los formatos digitales y de contenidos de acceso libre debiera estar en el centro de la discusión, pero no solo a nivel de los formatos de

11. Eco, U., Carrière, J.C., Nadie acabará con los libros, Barcelona: Lumen, 2010, pág. 102. 
los libros, sino de la cultura como parte de los derechos básicos. Una cultura no pensada por separado de la educación, como un derecho relacionado con las capacidades humanas en un sentido integral. De esta manera se supera la discusión de si es el dispositivo libro o el contenido (entretención, ocio o educativo) es lo que debe asegurarse, para centrarse así en el acceso amplio y libre centrado en lo que Martha Nussbaum define como un "paradigma o modelo de desarrollo humano", donde "lo que importa son las oportunidades o capacidades que posee cada persona en ciertas esferas centrales que abarcan desde la vida, la salud y la integridad física hasta la libertad política, la participación y la educación"12. Dentro de ese marco, la discusión acerca del futuro del libro y la lectura podría alcanzar un estrato que supere la preferencia en los formatos, de lo conocido a lo nuevo, y pasar a temas de acceso y de capacidad para hacer con lo que leemos otra cosa que no sea ser capaces de seguir instrucciones, sino también imaginar, soñar, incluso proyectar nuestras propias experiencias como elementos de transferencia de conocimiento para otros seres humanos.

Bauman en su libro del año 2011, La cultura en el mundo de la modernidad líquida, recoge el principio establecido por otros dos estudiosos de la sociedades contemporáneas que rompen la noción de estatus, gusto y clase asociados a la cultura ${ }^{13}$. Primero, John Goldthorpe, quien caracterizaría los comportamientos culturales de la actualidad como de indistinción de las jerarquías culturales. Es decir, que segmentos que tienen preferencias por la alta cultura también pueden interesarse por elementos populares. El segundo es Richard Petersen que acuña el concepto de "omnívoro" para describir el consumo cultural variado o indistinto por el que diferentes segmentos de la sociedad fluyen sin necesidad de estar apegados a una noción de gusto preciso.

De alguna manera la perspectiva que plantea esta indistinción de niveles culturales respecto de una actitud omnívora de consumo puede verse precisamente como el reflejo de su versión tecnológica, en la que no necesariamente los libros impliquen contenidos de alto nivel, ni los lectores una profundidad y fidelidad obligada a un tipo de dispositivo específico, el libro objeto. Es decir, busco lo que necesito en el medio y soporte en el que lo encuentre para leerlo, escucharlo, consumirlo, experimentarlo, memorizarlo, proyectarlo. Puede que escuche una novela en un audiolibro. Puedo ver la película hecha a partir de una novela, o la precuela de una serie que nace para la televisión pero que luego se transforma en cómic. Como sea, el sistema de transferencia medial se intensifica. Solíamos escuchar de nuestros padres el juicio asertivo que cualquier versión fílmica de una novela nunca alcanza la profundidad del original. Hoy esa noción de original no encuentra asiento en ningunos de los focos especializados. En el caso de las series de televisión es claro, los más adultos de una casa la verán semanalmente con la rigurosidad y expectación de la llegada del tren hace un siglo atrás. Los más jóvenes, recurrirán a canales alternativos como YouTube o, si se lo pueden permitir, descargar, pagando por Netflix u otra plataforma de este tipo o, simplemente, a través de plataformas "piratas".

12. Nussbaum, M., op. cit., 47.

13. Bauman, Z., La cultura en el mundo de la modernidad líquida, México: Fondo de Cultura Económica, 2013, pág. 10. 
Pero esta dinámica se dio ya con la llegada de los videos y el desarrollo de los sistemas de DVD's en los que la circulación paralela se daba en la misma medida que el desarrollo tecnológico rompía con la hegemonía de la posesión del material y la institución que lo gestionaba. Durante los primero cien años del cine, el público requirió de una sala y de una máquina que difícilmente permitía la autonomía individual y personalizada de la experiencia de un film. Tal como hace seiscientos años, cuando los libros eran manuscritos, la gran mayoría de esos escasos lectores debía tener acceso a una biblioteca, conventual, pública o universitaria para acceder a ellos. Luego con la evolución de la tecnología de impresión los libros fueron más accesibles pero tardaron mucho en lograr un contexto paralelo a los requerimientos de compra y acceso institucionales. Los libros usados nunca amenazaron las librerías que los venden nuevos. Por qué ahora sí nos parece que las variantes de acceso a estas economías de reventa y reciclaje nos resultan apocalípticas. Solo la llegada masiva y doméstica de los medios de reproducción como la fotocopiadora, en los años setenta del siglo XX, permitieron una versión preliminar de lo que hoy se llama directamente un producto "pirata". Eran parte de los subproductos derivados de la invención de la fotografía, concretada un siglo antes aproximadamente. La distancia era enorme. Entre el libro como tal y el objeto resultante de la copia y anillado de las hojas tratadas con un proceso fotosensible que venía desarrollándose desde la década de 1930. De todos modos, eso implicaba igualmente la necesidad de tener un original o al menos una versión del libro que se quería copiar. Durante todos estos años, la fotocopia no logró amenazar el universo del libro. Pocas voces se alzaron para describirlo como el enemigo real de la lectura. Lo mismo con la proliferación del comercio de la piratería fílmica, aunque represente una actividad ilegal y mantenga un sistema paralelo de economías, el cine no ha muerto y su industria parece saludable. Aunque es verdad que ha debido, al igual que la música y el negocio discográfico, buscar formas de financiamiento paralelo para sostener lo que antes era un universo cautivo. Los cassettes, esas formas arcaicas de grabación y reproducción de audio, nunca anunciaron el fin de la música. Hoy, las plataformas de acceso y la Internet permiten describir un universo complejo de mantenimiento entre los productores y los músicos, respecto de los fans. Una excelente recomendación para morigerar esta tendencia es escuchar la voz de dos decanos de la cultura, al mismo tiempo modernos y sabios, Umberto Eco y Jean-Claude Carrière, en Nadie acabará con los libros. En uno de los primeros diálogos que reproduce, Eco afirma: "Las variaciones en torno al objeto libro no han modificado su función, ni su sintaxis, desde hace más de quinientos años. El libro es como la cuchara, el martillo, la rueda, las tijeras. Una vez que se ha inventado, no se puede hacer nada mejor" ${ }^{14}$.

Para concluir, en cada una de las áreas en las que hemos transitado para graficar un ritmo de aparición, desarrollo y obsolescencia de los dispositivos de los que la sociedad se ha servido para acuñar, almacenar y reproducir la información, se demuestra que en vez de escandalizarnos cada cierto tiempo con los ritmos de recambio de la tecnología de reproducción y de los materiales mismos en los que se plasma la información, debemos asumir que se trata de una dinámica inevitable. Ciclos, o si se quiere, para

14. Eco, U., op. cit., pág. 20. 
volver a Bauman y Simmel, de ciclos generacionales. Esto nos enfrenta nuevamente a preguntarnos por cuáles deben ser los lineamientos que pudieran apoyar una forma de solidaridad ante los pesares que hemos descrito como congénitos para quienes llegan por primera vez a este mundo inestable del libro y la lectura, y degenerativos, para quienes ven horrorizados cómo el mundo en el que crecieron y se formaron se transforma. Lineamientos que por cierto deben superar los intereses de un formato específico al que se le atribuyen valores casi mágicos tanto de aprendizaje como de ocio, como puede ser los libros impresos. Asimismo como, con igual fuerza, se cargan mágicamente los soportes digitales con la huella de ser el principio del fin de la cultura. Más aun cuando además todo se complica al romperse la brecha que podría haber servido para separar nuevamente uno de otro los extremos del futuro del libro y la lectura, relativo a elementos de estatus cultural con criterios claros como nobleza o vulgaridad. El nuevo escenario, tal como plantea Bauman, es trasversal, omnívoro e indistinto. Al mismo tiempo las audiencias, espectadores, lectores no se sienten completamente identificados con una forma o un contenido específico, con una corriente artística u otra. Lectores o usuarios pueden preferir solo una parte o segmento del panorama cultural, así como constituirse ellos mismos en una parte o un segmento cultural y, en otro sentido dejar de serlo; o seguir siéndolo sin que eso signifique su exclusión de tópicos completamente opuestos como culto o inculto, analfabeto o letrado. Esto puede verse desde dos ángulos contrapuestos, en palabras de Bauman, "sentirme en casa en todas partes [así como, sentir que] no existe ningún lugar que pueda llamar mi casa"15. Es decir, al mismo tiempo y no de modo excluyente, culto y popular, ya no son excluyentes.

Los amantes del pasado demandan la restitución de un modelo de producción de conocimiento que favorece su miedo a abandonar el papel. Los enamorados del futuro reniegan de toda una tradición de lectores que aprendieron entre los lomos de los libros. Unos quieren dormir entre páginas, otros quieren disolverlas en el océano digital. La solución requiere mediar entre ambas posiciones. Crear lugares de encuentro en las instituciones. Hoy, más que en ningún otro momento, los museos y las bibliotecas vuelven a ser la habitación en que el pasado y el futuro se miran. Necesitamos imaginación institucional para revitalizar el antiguo equilibrio entre un espacio que, al mismo tiempo, guarda los tesoros del pasado y promete las herramientas para esperanzas inéditas. Libros análogos y digitales. Cuadernos y tablets son parte de esa nueva institucionalidad del saber, una que supera la arquitectura, la piedra del umbral académico y abre un frontispicio virtual efectivamente amplio. Usemos los formatos como medios para ampliar los lectores, las audiencias, los espectadores. Todos, a su modo, quieren leer. Mezclemos sus posibilidades e historias. Ocupados lectores, volvamos a pensar un ideal de cultura en común.

15. Bauman, Z., op. cit., pág. 22. 


\section{BIBLIOGRAFÍA}

Bauman, Z., La cultura en el mundo de la modernidad líquida, México: Fondo de Cultura Económica, 2013.

- La cultura como praxis, Barcelona: Paidós, 2009.

Bennett, S., Maton, K., Kervin, L., "The 'digital natives' debate: A critical review of the evidence", en British Journal of Educational Technology, 39 (5), 2008, págs. 775-786.

Darton, R., The Case of Books: Past, Present, Future, New York: Public Affairs, 2009.

Eco, U., Carrière, J.C., Nadie acabará con los libros, Barcelona: Lumen, 2010

Nussbaum, M., Sin fines de lucro: Por qué la democracia necesita de las humanidades, Buenos Aires: Katz, 2010.

Prensky, M., "Digital Natives, Digital Immigrants", en On the Horizon 9 (5), 2001.

Mansell, R., Wehn, U., Knowledge Societies: Information Technology for Sustainable Developmen, Oxford: Oxford University Press, 1998.

Platón, Fedro, Madrid: Gredos, 1988.

Simmel, G., "Sobre filosofía de la cultura: el concepto y la tragedia de la cultura", en Sobre la aventura, Barcelona: Península, 2002.

UNESCO, "Hacia las Sociedades del Conocimiento", coord. Günther Cyranek, 2005, véase online en http://unesdoc.unesco.org/images/0014/001419/141908s.pdf 